Check for updates

Cite this: RSC Adv., 2019, 9, 11077

Received 24th January 2019

Accepted 4th April 2019

DOI: $10.1039 / c 9 r a 00642 g$

rsc.li/rsc-advances

\section{Antioxidant activity of cerium dioxide nanoparticles and nanorods in scavenging hydroxyl radicals $\uparrow$}

\author{
Alexander Filippi, $\$^{\mathrm{a}}$ Fobang Liu, $\neq^{\mathrm{ab}}$ Jake Wilson, ${ }^{a}$ Steven Lelieveld, (D) a \\ Karsten Korschelt, ${ }^{c}$ Ting Wang, ${ }^{\text {ad }}$ Yueshe Wang, ${ }^{d}$ Tobias Reich, ${ }^{e}$ Ulrich Pöschl, (DD a \\ Wolfgang Tremel (iD ${ }^{c}$ and Haijie Tong (D) *a
}

\begin{abstract}
Cerium oxide nanoparticles (CeNPs) have been shown to exhibit antioxidant capabilities, but their efficiency in scavenging reactive oxygen species (ROS) and the underlying mechanisms are not yet well understood. In this study, cerium dioxide nanoparticles (CeNPs) and nanorods (CeNRs) were found to exhibit much stronger scavenging activity than $\cdot \mathrm{OH}$ generation in phosphate buffered saline (PBS) and surrogate lung fluid (SLF). The larger surface area and higher defect density of CeNRs may lead to higher $\cdot \mathrm{OH}$ scavenging activity than for CeNPs. These insights are important to understand the redox activity of cerium nanomaterials and provide clues to the role of CeNPs in biological and environmental processes.
\end{abstract}

Reactive oxygen species (ROS) generally describe reduction products of oxygen molecules, including $\mathrm{H}_{2} \mathrm{O}_{2}$ and hydroxyl radicals $(\cdot \mathrm{OH}) .{ }^{1} \mathrm{ROS}$ play a central role in biological processes exerting both beneficial and adverse health effects. ${ }^{2}$ Several studies have looked into the redox balance between ROS and antioxidants ${ }^{3}$ as well as the underlying mechanisms. ${ }^{4}$ Among all ROS, $\cdot \mathrm{OH}$ is considered as one of the most reactive species; it can attack biomolecules and cause irreversible damage. ${ }^{5}$ Thus, experimental quantification and abiotic regulation of $\cdot \mathrm{OH}$ under physiologically relevant conditions is an important yet challenging task.

In the last decade, cerium dioxide nanoparticles (CeNPs) have drawn much attention due to their redox properties ${ }^{6}$ and potential therapeutic applications (such as treating cardiac ischemia). ${ }^{7-9}$ Efforts have been made to explore the potential use of CeNPs as medicine., ${ }^{7,10,11}$ The ability of CeNPs in switching the oxidation state of $\mathrm{Ce}^{3+}$ and $\mathrm{Ce}^{4+}$ makes it a good candidate to mediate ROS. ${ }^{6,12}$ Direct scavenging of $\cdot \mathrm{OH}$ (process (1) in Scheme 1), NO·, and $\mathrm{OONO}^{-}$by CeNPs have been investigated. ${ }^{13-16}$ Moreover, previous studies indicated that CeNPs have

${ }^{a}$ Multiphase Chemistry Department, Max Planck Institute for Chemistry, Mainz, 55128, Germany.E-mail: h.tong@mpic.de

${ }^{b}$ School of Chemical and Biomolecular Engineering, Georgia Institute of Technology, Atlanta, Georgia 30332, USA

'Institute for Inorganic Chemistry and Analytical Chemistry, Johannes Gutenberg University Mainz, Mainz, 55128, Germany

${ }^{d}$ State Key Laboratory of Multiphase Flow in Power Engineering, Xi'an Jiaotong University, Xi'an 710049, China

'Institute of Nuclear Chemistry, Johannes Gutenberg University Mainz, Mainz, 55099, Germany

$\dagger$ Electronic supplementary information (ESI) available. See DOI: 10.1039/c9ra00642g

$\ddagger$ Both authors contributed equally to this work. catalase- and superoxide dismutase (SOD)-like effects (processes (3) and (5) in Scheme 1). ${ }^{17,18}$ Both effects are closely correlated with the $\mathrm{Ce}^{3+}$ and $\mathrm{Ce}^{4+}$ surface concentrations, $\mathrm{pH}$, $\mathrm{H}_{2} \mathrm{O}_{2}$ and chelating ligand concentrations. ${ }^{19-23}$

In contrast to research about the antioxidant activity of CeNPs, inhalable CeNPs have been detected in ambient air and concerns have been raised about their potential adverse health effect. ${ }^{24,25}$ Besides this, additional studies suggested that CeNPs can induce oxidative stress, inflammatory signaling response, and cell death upon generating ROS (processes (4)-(6) in Scheme 1) or ROS-messengers. ${ }^{26-30}$ Given the controversies about the beneficial and toxic effects of CeNPs, it is necessary to distinguish the anti- and prooxidant activities of CeNPs under physiologically relevant conditions. ${ }^{31}$ In this study, we compared the

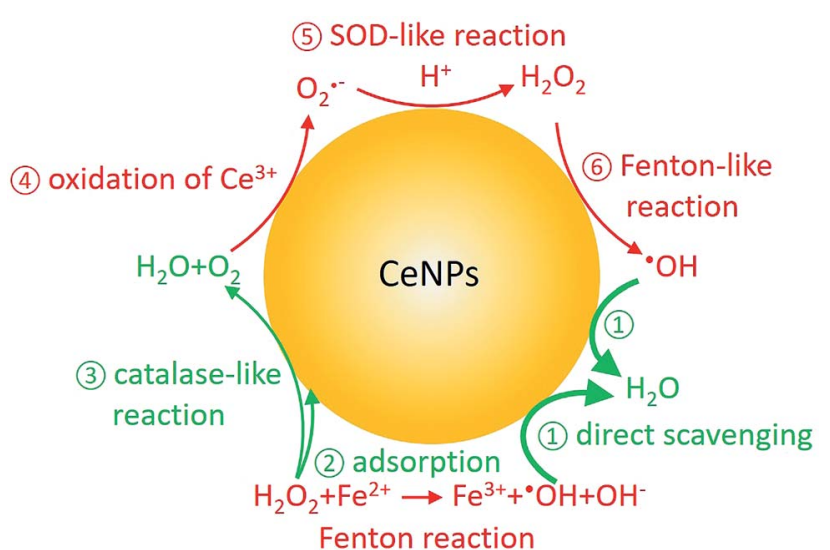

Scheme 1 Fenton reaction and reactive oxygen chemistry of CeNPs. Red and green colors indicate ROS formation and scavenging processes, respectively. 
- OH formation and scavenging ability of commercial CeNPs $(\varnothing$ 25 and $50 \mathrm{~nm}$ ) and homemade cerium nanorods (CeNRs) with different physicochemical properties in phosphate buffered saline (PBS) buffer, antioxidant solutions, and a surrogate lung fluid (SLF). The SLF was used to mimic the key interface between human respiratory tract and inhaled air.

Fig. 1 shows the size, morphology, surface composition, and mass normalized surface area of CeNPs and cerium dioxide nanorods (CeNRs). More information about the applied techniques, sample handling and instrument settings is compiled in Sections S1-S5. $\dagger$ Fig. 1A and B indicate that CeNPs ( $\varnothing 50 \mathrm{~nm})$ and CeNPs $(\varnothing 25 \mathrm{~nm})$ have a heterogeneous size distribution with average diameters of $<50 \mathrm{~nm}$ and $<25 \mathrm{~nm}$ respectively. Moreover, samples of these commercial CeNPs contain predominantly cubic NPs. In contrast, the morphology of CeNRs (Fig. 1C) is more uniform with a length of $\sim 100 \mathrm{~nm}$. Details about the CeNRs can be found from our previous study. ${ }^{32}$ In addition to the detection of size and morphology, the specific surface areas of the cerium nanoparticles were determined to be $24.8 \pm 0.4 \mathrm{~m}^{2} \mathrm{~g}^{-1}(\varnothing 50 \mathrm{~nm}$ CeNPs) (Fig. 1D), $39.2 \pm$ $0.7 \mathrm{~m}^{2} \mathrm{~g}^{-1}\left(\varnothing 25 \mathrm{~nm}\right.$ CeNPs) (Fig. 1E), and $106.5 \pm 2.4 \mathrm{~m}^{2} \mathrm{~g}^{-1}$ (CeNRs) (Fig. 1F). Moreover, the similar Ce 3d XPS spectra of CeNPs $(\varnothing 50 \mathrm{~nm})$ (Fig. 1G), CeNPs $(\varnothing 25 \mathrm{~nm})$ (Fig. 1H), and CeNRs (Fig. 1I) indicate that the distribution of the cerium surface oxidation states $\left(\mathrm{Ce}^{3+}\right.$ and $\left.\mathrm{Ce}^{4+}\right)$ on these NPs are quite similar. The six most prominent peaks of these spectra are attributable to $\mathrm{Ce}^{4+}$ ions. ${ }^{33}$ This indicates that $\mathrm{Ce}^{4+}$ was the dominant cerium species in all three samples. The peak fittings (dashed lines) in panels G, H and I are based on the method by
(A)

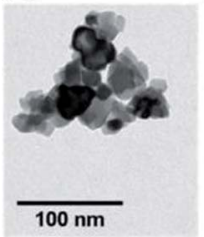

(D)

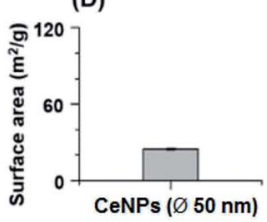

(G)

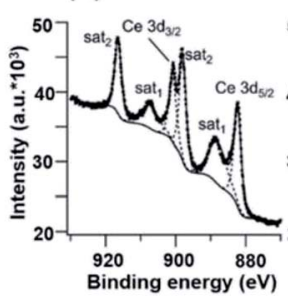

(B)

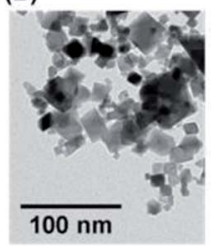

(E)

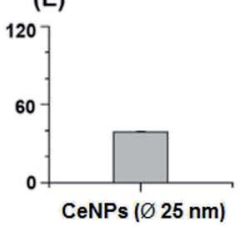

(H)

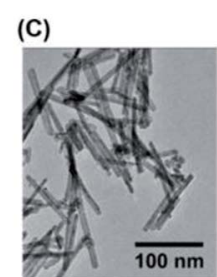

(F)

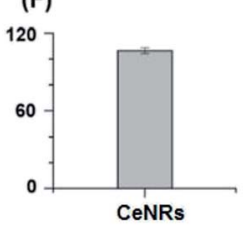

(I)

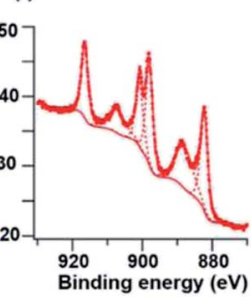

Fig. 1 Physicochemical characteristics of CeNPs ( $\varnothing 50 \mathrm{~nm})(A, D$, and $G)$, CeNPs $(\varnothing 25 \mathrm{~nm})(B, E$, and $H)$, and CeNRs (C, F, and I). (A-C) TEM images. (D-F) Surface areas determined by BET. (G-I) Ce 3d XPS spectra. The error bars in panels $(D-F)$ represent standard deviations based on three replicates. The dashed lines in panels $(G-l)$ are fitting curves.
Maslakov et al. ${ }^{33}$ The fitting based deconvolution of Ce 3d XPS spectra indicates that the concentration of surface $\mathrm{Ce}^{3+}$ in all these samples is $<3 \%$. Such a low abundance of surface $\mathrm{Ce}^{3+}$ is also supported by the absence of a shoulder peak of Ce $4 \mathrm{f}$ electrons at $\sim 1.1 \mathrm{eV}$ in the XPS valence band spectrum of the CeNRs samples (Fig. S3†). Furthermore, the deconvolution of the XPS spectrum of the O 1s region of the NPs (Fig. S2 and Table S3†) indicates that the CeNRs surface contains a much higher concentration of hydroxide than CeNPs. This may correlate with the synthesis method of CeNRs using $\mathrm{NaOH}$ as reagent $^{34}$ and may play a role in the higher $\cdot \mathrm{OH}$ scavenging activity of CeNRs. These differences in chemical composition, morphology, and surface area between CeNPs and CeNRs may result in variations of their redox activity.

Fig. 2 shows the trapping mechanism of 5-tert-butoxycarbonyl-5-methyl-1-pyrroline- $N$-oxide (BMPO, panel A) and EPR spectra of aqueous mixtures of $\mathrm{Fe}^{2+}, \mathrm{H}_{2} \mathrm{O}_{2}$, SLF, and CeNPs (panel B). Fig. 2A shows that BMPO can react with $\mathrm{OH}$ radicals and form a BMPO-OH radical adduct. In this way, short lifetime radicals can be probed and characterized by electron paramagnetic resonance (EPR) spectroscopy (EMXplus10/12, Bruker, Germany, see details in Section S5 and Table S4†). The grey dashed lines in panel $\mathrm{B}$ indicate the characteristic hyperfine splitting of $\mathrm{BMPO}-\mathrm{OH}$, in agreement with previous assignment. ${ }^{35}$ The peak intensities of the spectra in Fig. 2B decrease in the order $\mathrm{A}\left(\mathrm{Fe}^{2+}+\mathrm{H}_{2} \mathrm{O}_{2}\right)>\mathrm{B}\left(\mathrm{Fe}^{2+}+\mathrm{H}_{2} \mathrm{O}_{2}+\mathrm{CeNPs}\right)>$ $\mathrm{C}\left(\mathrm{Fe}^{2+}+\mathrm{H}_{2} \mathrm{O}_{2}+\mathrm{SLF}\right)>\mathrm{D}\left(\mathrm{Fe}^{2+}+\mathrm{H}_{2} \mathrm{O}_{2}+\mathrm{CeNPs}+\mathrm{SLF}\right)$. This implies that the amount of $\cdot \mathrm{OH}$ decreases accordingly. Based on the spin-counting method, ${ }^{32}$ we quantified the concentration of BMPO-OH in these solutions. The results are shown in Fig. 3 and Tables S5-S7.†

Fig. 3A and B show the positive correlation of $\cdot \mathrm{OH}$ yields of CeNPs $(\varnothing 50 \mathrm{~nm})$ without (black circles) and with the addition of $\mathrm{H}_{2} \mathrm{O}_{2}$ (black triangles) under different CeNPs $(\varnothing 50 \mathrm{~nm}$ ) loading conditions. In the absence of $\mathrm{H}_{2} \mathrm{O}_{2}, 0.1-30 \mathrm{mg} \mathrm{mL}$

(A)

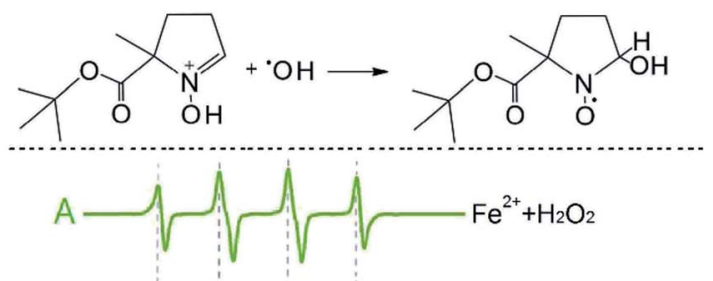

(B)

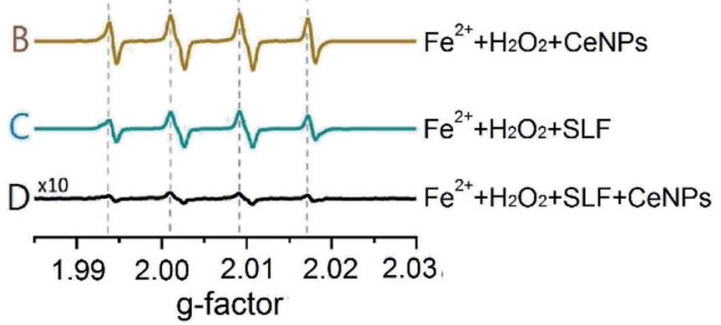

Fig. 2 (A) Reaction mechanism of the spin-trapping agent BMPO with a hydroxyl radical. (B) EPR spectra of the BMPO-radical adduct in different aqueous mixtures. The four peaks (dotted lines) are characteristic of BMPO-OH adducts. The concentrations of $\mathrm{Fe}^{2+}, \mathrm{H}_{2} \mathrm{O}_{2}$, and CeNPs $(\varnothing 50 \mathrm{~nm})$ are $1 \mathrm{mM}, 10 \mathrm{mM}$, and $10 \mathrm{mg} \mathrm{mL}^{-1}$, respectively. 

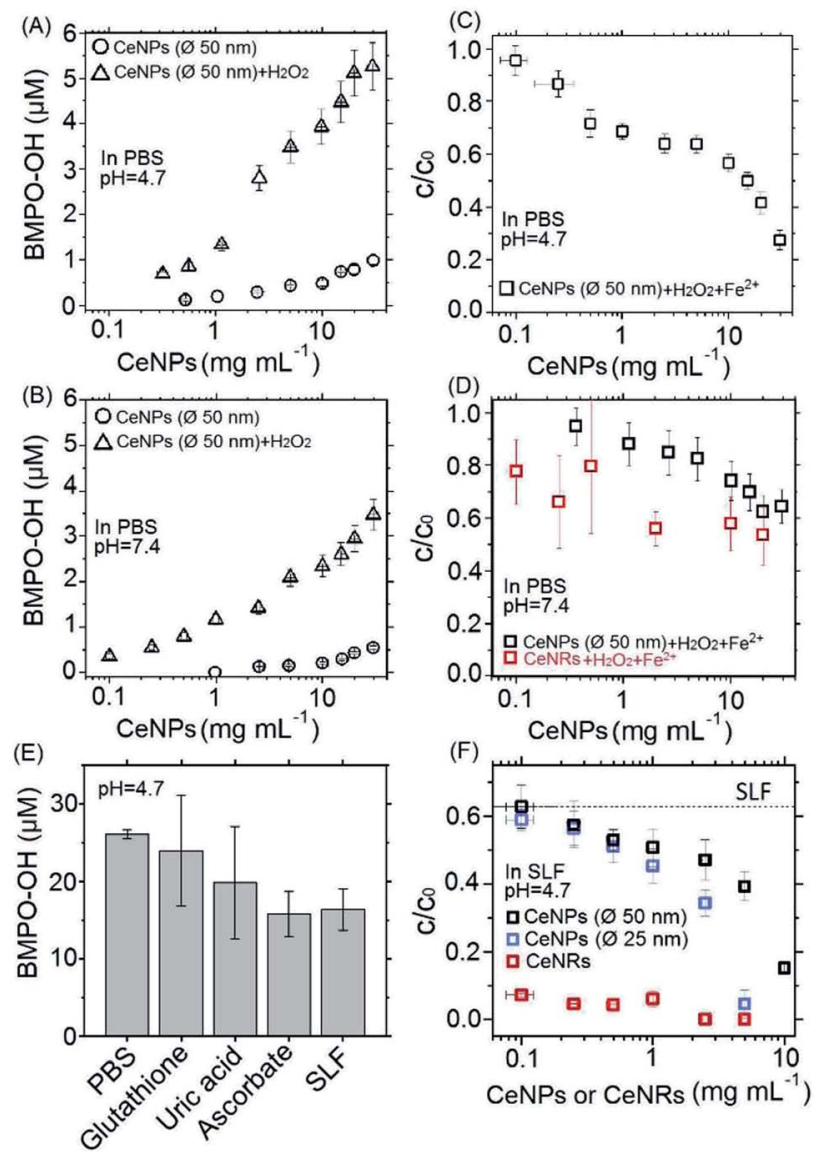

Fig. 3 Concentrations ( $A, B$, and $E$ ) or remaining fractions $(C, D$, and $F)$ of $\mathrm{BMPO}-\mathrm{OH}$ in different aqueous mixtures. (A) and (B) Concentrations of BMPO-OH formed by pure CeNPs $(\varnothing 50 \mathrm{~nm})(O)$ or their mixtures within $\mathrm{H}_{2} \mathrm{O}_{2}(\Delta)$ in $\mathrm{pH}=4.7$ (A) and 7.4 (B) PBS. (C) and (D) Remaining fraction $\left(c / c_{0}\right)$ of BMPO-OH without $\left(c_{0}\right)$ and with $(c)$ mixing CeNPs $(\varnothing 50 \mathrm{~nm})$ or CeNRs $(\square)$ with $1 \mathrm{mM} \mathrm{Fe}^{2+}$ and $10 \mathrm{mM}$ $\mathrm{H}_{2} \mathrm{O}_{2}$ in $\mathrm{pH}=4.7$ (C) and 7.4 (D) PBS. (E) Concentration of BMPO-OH formed by Fenton reactions in neutral PBS, antioxidant solutions, and SLF. (F) $c / c_{0}$ of BMPO-OH with and without mixing CeNPs $(\varnothing 50 \mathrm{~nm})$ ( $\square)$, CeNPs $(\varnothing 25 \mathrm{~nm})(\square)$, and CeNRs $(\square)$ with $1 \mathrm{mM} \mathrm{Fe}^{2+}$ and $10 \mathrm{mM}$ $\mathrm{H}_{2} \mathrm{O}_{2}$ in $\mathrm{pH}=4.7 \mathrm{SLF}$. The values of $\mathrm{C}_{0}$ in panels $\mathrm{B}, \mathrm{D}$ and $\mathrm{F}$ are $\sim 53$, $\sim 17$, and $\sim 26 \mu \mathrm{M}$. The $x$-axis errors in panels $A, B, C, D$, and $F$ represent uncertainties from weighing and pipetting. All the $y$-errors represent standard deviation of more than three replicates.

CeNPs $(\varnothing 50 \mathrm{~nm})$ can generate $0-0.8$ and $0-0.5 \mu \mathrm{M} \cdot \mathrm{OH}$ in $\mathrm{pH}=$ 4.7 (Fig. 3A) and 7.4 (Fig. 3B) PBS, respectively. The generation of $\cdot \mathrm{OH}$ by pure CeNPs $(\varnothing 50 \mathrm{~nm})$ in acidic PBS is consistent with previous hypothesis that acid can catalyze the $\cdot \mathrm{OH}$ formation by CeNPs. ${ }^{36}$ In contrast to pure CeNPs $(\varnothing 50 \mathrm{~nm})$, mixtures of $0.1-$ $30 \mathrm{mg} \mathrm{mL}{ }^{-1}$ CeNPs $(\varnothing 50 \mathrm{~nm})$ with $10 \mathrm{mM}$ of $\mathrm{H}_{2} \mathrm{O}_{2}$ can generate $0-5(\mathrm{pH}=4.7)$ and $0-3 \mu \mathrm{M}(\mathrm{pH}=7.4) \cdot \mathrm{OH}$, which also shows a positive correlation with the loading of CeNPs $(\varnothing 50 \mathrm{~nm})$ as shown in Fig. 3A and B. These hydroxyl radicals may be formed through Fenton-like reactions initiated by CeNPs: ${ }^{37} \mathrm{H}_{2} \mathrm{O}_{2}+\mathrm{Ce}^{3+}$ $\rightarrow \mathrm{Ce}^{4+}+\cdot \mathrm{OH}+\mathrm{OH}^{-}$.

To evaluate the $\cdot \mathrm{OH}$ scavenging activity of CeNPs in aqueous solution, we measured the $\cdot \mathrm{OH}$ yield by mixtures of CeNPs $(\varnothing$ $50 \mathrm{~nm}$ ) or CeNRs, $\mathrm{Fe}^{2+}$, and $\mathrm{H}_{2} \mathrm{O}_{2}$ in acidic and neutral PBS.
Fig. $3 \mathrm{C}$ and $\mathrm{D}$ show that the $\cdot \mathrm{OH}$ concentration decreased with increasing CeNPs or CeNRs loading, characterized by the decreasing remaining $\mathrm{OH}$ radical concentration. In the absence of CeNPs, Fenton reactions of $1 \mathrm{mM} \mathrm{Fe}^{2+}$ and $10 \mathrm{mM} \mathrm{H}_{2} \mathrm{O}_{2}$ generated $\sim 53$ and $\sim 17 \mu \mathrm{M} \cdot \mathrm{OH}$ in $\mathrm{pH}=4.7$ (Fig. 3C) and 7.4 (Fig. 3D) PBS. At $30 \mathrm{mg} \mathrm{mL} \mathrm{m}^{-1}$ CeNPs $(\varnothing 50 \mathrm{~nm})$, concentration of $\cdot \mathrm{OH}$ decreased to $15 \mu \mathrm{M}(\mathrm{pH}=4.7)$ and $11 \mu \mathrm{M}(\mathrm{pH}=7.4)$, respectively (Tables S5 and S6†). In contrast to CeNPs, CeNRs exhibited higher $\cdot \mathrm{OH}$ scavenging efficiency, with $20-50 \%$ of . $\mathrm{OH}$ to be scavenged by $0.1-20 \mathrm{mg} \mathrm{mL}^{-1}$ CeNRs. This implies that the scavenging activity of CeNPs $(\varnothing 50 \mathrm{~nm})$ is more pronounced under acidic conditions. The decrease of $\cdot \mathrm{OH}$ concentration may be induced by the following processes: first, CeNPs $(\varnothing 50 \mathrm{~nm})$ or CeNRs could scavenge $\cdot \mathrm{OH}$ directly (process (1) in Scheme 1). ${ }^{13}$ Second, the adsorption of $\mathrm{H}_{2} \mathrm{O}_{2}$ on CeNPs ( $\varnothing 50 \mathrm{~nm}$ ) or CeNRs surfaces (like process (2) in Scheme 1) may decrease the available $\mathrm{H}_{2} \mathrm{O}_{2}$ concentration. ${ }^{38}$ In this case, due to the lower availability of the $\mathrm{H}_{2} \mathrm{O}_{2}$ precursor, the amount of $\cdot \mathrm{OH}$ formed by Fenton reactions will decrease. Third, the surface-bound $\mathrm{H}_{2} \mathrm{O}_{2}$ can be decomposed via catalase-like reactions (process (3) in Scheme 1). ${ }^{21}$ This process will form $\mathrm{H}_{2} \mathrm{O}$ and $\mathrm{O}_{2}$ rather than $\mathrm{OH}$. Beyond these two pathways, iron ioninitiated redox processes may also influence the measured - $\mathrm{OH}$ concentrations. For instance, it has been suggested that upon interaction with the surface of CeNPs, $\mathrm{Fe}^{2+}$ can enhance the dissolution of $\mathrm{Ce}^{3+}$ and cause the formation of 6-line ferrihydrite, which can increase the colloidal stability of the CeNPs. ${ }^{39}$ Such a reaction may alter the redox activity of CeNPs $(\varnothing 50 \mathrm{~nm})$ or CeNRs.

Recently Baldim et al. ${ }^{38}$ measured the $\mathrm{H}_{2} \mathrm{O}_{2}$ surface adsorption potential of CeNPs with different sizes. They found that 5$28 \mathrm{~nm}$ diameter CeNPs could adsorb 2-20 $\mathrm{H}_{2} \mathrm{O}_{2}$ molecules $\mathrm{nm}^{-2}$, depending on the surface composition of the nanomaterial. We used the adsorption potential from Baldim et al. and estimated that only $<1 \%$ of $\mathrm{H}_{2} \mathrm{O}_{2}(\sim 8 \mu \mathrm{M})$ can be adsorbed on the surface of the CeNPs. Therefore, the surface adsorption of $\mathrm{H}_{2} \mathrm{O}_{2}$ by CeNPs cannot fully explain the reduction of $\cdot \mathrm{OH}$ concentration in Fig. 3. Furthermore, Pirmohamed et al. ${ }^{21}$ observed a $\mathrm{H}_{2} \mathrm{O}_{2}$ decomposition rate of $\sim 2.7 \mathrm{nmol} \mathrm{min}^{-1}$ through catalase-like reactions. Based on this value, we estimate that a concentration of $0.1 \mathrm{mg} \mathrm{mL}^{-1}$ of CeNPs would result in a $\mathrm{H}_{2} \mathrm{O}_{2}$ loss of $<2 \%$ in our studies. Therefore, we suggest the direct scavenging process (1) in Scheme 1), rather than the surface adsorption (2) in Scheme 1) and catalase-like (3)in Scheme 1) processes to be the dominant reduction pathways of . OH.

Fig. 3E shows the $\cdot \mathrm{OH}$ scavenging activity of typical epithelial lung fluid antioxidants and a surrogate lung fluid (SLF). Here, $0.1 \mathrm{mM}$ of glutathione, $0.1 \mathrm{mM}$ of uric acid, and $0.2 \mathrm{mM}$ of ascorbate solutions could scavenge $\sim 8 \%, \sim 14 \%$, and $\sim 39 \%$ of hydroxyl radicals originating from Fenton reactions of $1 \mathrm{mM}$ $\mathrm{Fe}^{2+}$ and $10 \mathrm{mM} \mathrm{H}_{2} \mathrm{O}_{2}$ in PBS. The SLF showed a similar activity as $0.2 \mathrm{mM}$ ascorbate, i.e. the $\cdot \mathrm{OH}$ scavenging activities of individual antioxidants are not additive and decrease in the order ascorbate $>$ uric acid $>$ glutathione. This trend is consistent with previous findings. ${ }^{38}$ 
To assess the antioxidant activity of CeNPs under quasiphysiological conditions, we explored the $\cdot \mathrm{OH}$ scavenging activity of CeNPs and CeNRs in SLF. Fig. 3F shows the hydroxyl radical yield by Fenton reactions in SLF as a function of the CeNPs $(\varnothing 25$ and $50 \mathrm{~nm}$ ) and CeNRs loading. As the loading of CeNPs $(\varnothing 50 \mathrm{~nm})$ increased from 0.1 to $10 \mathrm{mg} \mathrm{mL}{ }^{-1}$, the concentration of $\cdot \mathrm{OH}$ in SLF decreased by $38-85 \%$. Within the same loading range, the CeNPs $(\varnothing 25 \mathrm{~nm})$ exhibited a similar efficiency. Whereas at higher loadings (1-5 $\left.\mathrm{mg} \mathrm{mL}^{-1}\right)$, the $\cdot \mathrm{OH}$ scavenging potential of CeNPs $(\varnothing 25 \mathrm{~nm})$ was $9-55 \%$ higher than that of their $50 \mathrm{~nm}$ counterparts. In contrast to CeNPs, the CeNRs showed a much higher $\cdot \mathrm{OH}$ scavenging efficiency. Even with a loading as low as $0.1 \mathrm{mg} \mathrm{mL}^{-1}$, the CeNRs could reduce $88 \%$ of the $\mathrm{OH}$. For CeNRs loadings that exceeded $1 \mathrm{mg} \mathrm{mL}{ }^{-1}$, no $\cdot \mathrm{OH}$ could be observed. The trend of the $\cdot \mathrm{OH}$ scavenging efficiency according to CeNRs $>$ CeNPs $(\varnothing 25 \mathrm{~nm})>\operatorname{CeNPs}(\varnothing 50$ $\mathrm{nm}$ ) is in the same order as the surface area of these NPs (Fig. 1D-F). Given the low abundance of $\mathrm{Ce}^{3+}$ on fresh CeNPs and CeNRs surface (Fig. 1G-H), we suggest that substantial amount of $\mathrm{Ce}^{3+}$ may be formed upon interactions of NPs with water. ${ }^{13}$ The larger surface area of CeNRs may increase the density of $\mathrm{Ce}^{3+}$ per unit particle mass and subsequently their - OH scavenging activity. Previous works showed that CeNRs are prone to expose their (110) facets to reactive species. ${ }^{34}$ These facets were described as reactive "hybrid structures" between the (111) and (100) surfaces of CeNPs. Furthermore, the distinct crystallographic surface structure of CeNRs may act as binding site for reactive species $\left(\cdot \mathrm{OH}\right.$ and $\mathrm{H}_{2} \mathrm{O}_{2}$ ) exerting peroxidase-like effects. Additionally, $\mathrm{Fe}^{2+}$-dependent reactive oxygen chemistry may contribute to the observed $\cdot \mathrm{OH}$ scavenging processes. ${ }^{39}$ Finally, it has been suggested that glutathione could interact with CeNPs and influence the redox couple of $\mathrm{Ce}^{3+} / \mathrm{Ce}^{4+} \cdot{ }^{40}$

It is worthy to note that a real physiologic environment is more complicated than SLF. A large number of redox chemistry processes may alter the agglomeration and distribution of CeNPs and relevant materials, ${ }^{\mathbf{4 1}}$ which may eventually influence its properties including $\cdot \mathrm{OH}$ scavenging efficiency and SOD-like characteristics. ${ }^{42}$ Thus, characterizing CeNPs or their functionalized derivatives in more realistic environments will be beneficial and promising in follow-up studies.

\section{Conclusions}

In this study, we compared the ability of CeNPs and CeNRs in scavenging hydroxyl radicals $(\cdot \mathrm{OH})$ under physiologically relevant conditions. We found that CeNPs and CeNRs exert high - $\mathrm{OH}$ scavenging activity in both PBS and SLF. In SLF, the $\cdot \mathrm{OH}$ scavenging potential of CeNPs increased 4 -fold as the loading increases from 0.1 to $10 \mathrm{mg} \mathrm{mL}^{-1}$. In the same loading range, CeNRs showed 5-50-fold higher $\cdot \mathrm{OH}$ scavenging potential than CeNPs, which may be attributable to the higher surface area and defect density of CeNRs. Furthermore, we found the scavenging activity of CeNPs is pH-dependent, exhibiting higher scavenging efficiency under lower $\mathrm{pH}$ condition. The observed $\cdot \mathrm{OH}$ scavenging efficiency of CeNPs and CeNRs in SLF took into account the effect of antioxidants at concentrations close to the epithelial lung fluid, reflecting the redox activity of CeNPs and
CeNRs under more realistic in vitro conditions than previous studies. These findings are of critical importance for a better understanding of the relative ROS scavenging efficiency of CeNPs comparing to conventional antioxidants. Moreover, these results are also important for making accurate doseresponse curves predicting the toxicity or antioxidant characteristics of CeNPs or their functionalized derivatives in biological and environmental processes.

\section{Conflicts of interest}

There are no conflicts to declare.

\section{Acknowledgements}

This work was funded by the Max Planck Society, the Deutsche Forschungsgemeinschaft (DFG), and the National Natural Science Foundation of China (No. 51576160). We thank Jakob Drebert for his support of the XPS measurements. Open Access funding provided by the Max Planck Society.

\section{Notes and references}

1 A. A. Alfadda and R. M. Sallam, J. Biomed. Biotechnol., 2012, 2012, 936486.

2 C. C. Winterbourn, Nat. Chem. Biol., 2008, 4, 278-286.

3 B. Poljsak, D. Suput and I. Milisav, Oxid. Med. Cell. Longevity, 2013, 2013, 956792.

4 S. B. Nimse and D. Pal, RSC Adv., 2015, 5, 27986-28006.

5 A. Phaniendra, D. B. Jestadi and L. Periyasamy, Indian J. Clin. Biochem., 2015, 30, 11-26.

6 A. Karakoti, S. Singh, J. M. Dowding, S. Seal and W. T. Self, Chem. Soc. Rev., 2010, 39, 4422-4432.

7 J. M. Perez, A. Asati, S. Nath and C. Kaittanis, Small, 2008, 4, 552-556.

8 S. Rajeshkumar and P. Naik, Biotechnol. Rep., 2018, 17, 1-5. 9 M. Culcasi, L. Benameur, A. Mercier, C. Lucchesi, H. Rahmouni, A. Asteian, G. Casano, A. Botta, H. Kovacic and S. Pietri, Chem.-Biol. Interact., 2012, 199, 161-176.

10 C. Walkey, S. Das, S. Seal, J. Erlichman, K. Heckman, L. Ghibelli, E. Traversa, J. F. McGinnis and W. T. Self, Environ. Sci.: Nano, 2015, 2, 33-53.

11 C. K. Kim, T. Kim, I. Y. Choi, M. Soh, D. Kim, Y. J. Kim, H. Jang, H. S. Yang, J. Y. Kim and H. K. Park, Angew. Chem., Int. Ed., 2012, 51, 11039-11043.

12 K. M. Dunnick, R. Pillai, K. L. Pisane, A. B. Stefaniak, E. M. Sabolsky and S. S. Leonard, Biol. Trace Elem. Res., 2015, 166, 96-107.

13 Y. Xue, Q. Luan, D. Yang, X. Yao and K. Zhou, J. Phys. Chem. C, 2011, 115, 4433-4438.

14 J. M. Dowding, T. Dosani, A. Kumar, S. Seal and W. T. Self, Chem. Commun., 2012, 48, 4896-4898.

15 J. M. Dowding, S. Seal and W. T. Self, Drug Delivery Transl. Res., 2013, 3, 375-379.

16 W. He, Y. Liu, W. G. Wamer and J. J. Yin, J. Food Drug Anal., 2014, 22, 49-63. 
17 C. Korsvik, S. Patil, S. Seal and W. T. Self, Chem. Commun., 2007, 10, 1056-1058.

18 Y. Yang, Z. Mao, W. Huang, L. Liu, J. Li, J. Li and Q. Wu, Sci. Rep., 2016, 6, 35344.

19 B. C. Nelson, M. E. Johnson, M. L. Walker, K. R. Riley and C. M. Sims, Antioxidants, 2016, 5, 15-36.

20 E. Grulke, K. Reed, M. Beck, X. Huang, A. Cormack and S. Seal, Environ. Sci.: Nano, 2014, 1, 429-444.

21 T. Pirmohamed, J. M. Dowding, S. Singh, B. Wasserman, E. Heckert, A. S. Karakoti, J. E. King, S. Seal and W. T. Self, Chem. Commun., 2010, 46, 2736-2738.

22 V. K. Ivanov, A. B. Shcherbakov and A. V. Usatenko, Russ. Chem. Rev., 2009, 78, 855-871.

23 V. Patel, M. Singh, E. L. H. Mayes, A. Martinez, V. Shutthanandan, V. Bansal, S. Singh and A. S. Karakoti, Chem. Commun., 2018, 54, 13973-13976.

24 C. Guo, S. Robertson, R. J. M. Weber, A. Buckley, J. Warren, A. Hodgson, J. Z. Rappoport, K. Ignatyev, K. Meldrum, I. Römer, S. Macchiarulo, J. K. Chipman, T. Marczylo, M. O. Leonard, T. W. Gant, M. R. Viant and R. Smith, Nanotoxicology, 2019, 1-18.

25 S. Dekkers, L. Ma-Hock, I. Lynch, M. Russ, M. R. Miller, R. P. Schins, J. Keller, I. Römer, K. Küttler and V. Strauss, Inhalation Toxicol., 2018, 30, 273-286.

26 A. Srinivas, P. J. Rao, G. Selvam, P. B. Murthy and P. N. Reddy, Toxicol. Lett., 2011, 205, 105-115.

27 E. J. Park, J. Choi, Y. K. Park and K. Park, Toxicology, 2008, 245, 90-100.

28 H. J. Eom and J. Choi, Toxicol. Lett., 2009, 187, 77-83.

29 E.-J. Park, W.-S. Cho, J. Jeong, J.-h. Yi, K. Choi, Y. Kim and K. Park, J. Health Sci., 2010, 56, 387-396.

30 M. S. Wason, J. Colon, S. Das, S. Seal, J. Turkson, J. Zhao and C. H. Baker, Nanomedicine, 2013, 9, 558-569.
31 H. Zhang, X. He, Z. Zhang, P. Zhang, Y. Li, Y. Ma, Y. Kuang, Y. Zhao and Z. Chai, Environ. Sci. Technol., 2011, 45, 37253730 .

32 K. Korschelt, R. Schwidetzky, F. Pfitzner, J. Strugatchi, C. Schilling, M. von der Au, K. Kirchhoff, M. Panthofer, I. Lieberwirth, M. N. Tahir, C. Hess, B. Meermann and W. Tremel, Nanoscale, 2018, 10, 13074-13082.

33 K. I. Maslakov, Y. A. Teterin, A. J. Popel, A. Y. Teterin, K. E. Ivanov, S. N. Kalmykov, V. G. Petrov, P. K. Petrov and I. Farnan, Appl. Surf. Sci., 2018, 448, 154-162.

34 K. Herget, P. Hubach, S. Pusch, P. Deglmann, H. Gotz, T. E. Gorelik, I. A. Gural'skiy, F. Pfitzner, T. Link, S. Schenk, M. Panthofer, V. Ksenofontov, U. Kolb, T. Opatz, R. Andre and W. Tremel, Adv. Mater., 2017, 29, 1603823.

35 H. Tong, P. S. J. Lakey, A. M. Arangio, J. Socorro, F. Shen, K. Lucas, W. H. Brune, U. Poschl and M. Shiraiwa, Environ. Sci. Technol., 2018, 52, 11642-11651.

36 W. Lin, Y. W. Huang, X. D. Zhou and Y. Ma, Int. J. Toxicol., 2006, 25, 451-457.

37 A. D. Bokare and W. Choi, J. Hazard. Mater., 2014, 275, 121135.

38 V. Baldim, F. Bedioui, N. Mignet, I. Margaill and J. F. Berret, Nanoscale, 2018, 10, 6971-6980.

39 X. Liu, J. R. Ray, C. W. Neil, Q. Li and Y. S. Jun, Environ. Sci. Technol., 2015, 49, 5476-5483.

40 F. Rollin-Genetet, C. Seidel, E. Artells, M. Auffan, A. Thiery and C. Vidaud, Chem. Res. Toxicol., 2015, 28, 2304-2312.

41 A. Nel, T. Xia, L. Madler and N. Li, Science, 2006, 311, 622627.

42 J. Wu, X. Wang, Q. Wang, Z. Lou, S. Li, Y. Zhu, L. Qin and H. Wei, Chem. Soc. Rev., 2019, 48, 1004-1076. 